\title{
The effect of motivational music on wingate anaerobic test performance $^{1}$
}

\author{
Özkan Iş1k ${ }^{2}$ \\ Yasin Ersöz $z^{3}$ \\ Murat Pazan ${ }^{4}$ \\ Yücel Ocak ${ }^{5}$
}

\begin{abstract}
The aim of this study is to examine the effect of the motivational music on the Wingate Anaerobic Test (WAnT) performance. 16 male students who studied at School of Physical Education and Sports, Kocatepe University participated in the study voluntarily. After demographic characteristics of the voluntaries [age, height, body weight (BW), body mass index (BMI)] were measured without music (pre-test) and with motivational music [>120 bpm (beats per minute)] conditions (post-test). For the analyses of the data; Wilcoxon Rank Test was used in order to detect the difference among the variables. As a result of the measurements taken in with and without music conditions; it was found out that there was a statistically significant difference on behalf of condition with music in terms of maximum anaerobic power $\left(\mathrm{M}_{\mathrm{ax}} \mathrm{AP}\right)$, maximum anaerobic capacity (MAC), relative anaerobic power (RAP), relative anaerobic capacity $(\mathrm{RAC})$ and fatigue index $(\mathrm{FI})$ values $(\mathrm{p}<0,05)$, while there was no statistically significant difference in terms of minimum anaerobic power $\left(\mathrm{M}_{\text {in }} \mathrm{AP}\right)$ values $(\mathrm{p}>0,05)$. It was determined that the motivational music has positive effects on the WAnT performance. However; although it was seen that motivational music increased the WAnT performance, we were of the opinion that this effect emerged thanks to the increased psycho-physiological factors caused by music.
\end{abstract}

Keywords: Wingate Anaerobic Test, Anaerobic Power, Motivational Music

\section{Introduction}

Recently, the music is commonly used as accompanying to the exercise and sports activities (Gacesa, Barak and Grujic, 2009; Koc, and Curtseit, 2009; Waterhouse, Hudson and Edwards, 2010). The studies made related to the music in the literature are generally about the psychological, psycho-physiological and ergogenic effects of the music. The studies regarding the effects of the

\footnotetext{
${ }^{1}$ The study was presented as a oral presentation at the 3rd International Conference on Science Culture and Sport in 24-26 May 2014. Sarajevo/Bosnia and Herzegovina.

2 Ph. D., Kocatepe University, School of Physical Education and Sports, ozkanisik86@,hotmail.com

${ }^{3}$ R. A., Kocatepe University, School of Physical Education and Sports, yasin ersz@hotmail.com

${ }^{4}$ Principal Clerk, Ministry of Youth and Sports, Ankara, muratpazan@gmail.com

${ }^{5}$ Assoc. Prof., Kocatepe University, School of Physical Education and Sports, yocak@aku.edu.tr
} 
Işık, Ö., Ersöz, Y., Pazan, M., \& Ocak, Y. (2015). The effect of motivational music on wingate anaerobic test performance. International Journal of Human Sciences, 12(2), 513-520. doi: $10.14687 /$ ijhs.v12i2.3254

music on the psychological mood (Callaghan and Growney, 2013), emotion (Perlovsky, 2014), attitude (Ataman, 2014), cognition (Schlaug et al., 2005), and behavior (Chang et al., 2008) of the individuals and about the psycho-physiologically generally rating of perceived exertion (RPE) (Yamashita et al. 2006; Mohammadzadeh, Tartibiyan \& Ahmadi, 2008), and that it has delayed the fatigue and increased the work capacity and even made better the physical performance ergogenically have been made (Terry and Karageorghis, 2011).

The studies revealing that the music listened at the different speeds during the exercise have different effects on the organism have been made (Elliott, Carr \& Orme, 2005; Atan, 2013). The music generally having high tempo $(>120 \mathrm{bpm})$ and memorable melodies, inspirational lyrics, and having a structure increasing and refreshing the sportive effort is called as the motivational music (Terry and Karageorghis, 2011). It has been declared that the performance components of the motivational music will increase some physiological and psychological factors and even the physical activity and sportive performance (Koc and Curtseit, 2009). However, whether the music has effect or not differs in the studies examining its effect on the WAnT (Wingate Anaerobic Test) performance (Pujol and Langenfeld, 1999; Atan, 2013). We think that the motivational music will increase the WAnT performance. The aim of this study this context is to examine the effect of the motivational music on the WAnT performance.

\section{Methods}

\section{Participants}

The sample of this research is composed of 16 male voluntary who studied at School of Physical Education and Sports, Kocatepe University. Following an initial familiarization session, participants attended the laboratory on two occasions separated by 3 days. Before the application, the required information about the test protocols was told to the voluntaries by the researchers.

\section{Selection of music}

The best of the last 10 years indigenous and foreign original and remix 50 music being $>120-130$ bpm were selected and listed by the researcher. The participants were included to the test by selecting the music that they wanted from the list in which 50 popular songs took place for the measurements in condition with music.

\section{WAnT Measurements}

The WAnT was performed on a computerized Monark Cycle ergometer (Model 874E, Varberg, Sweden). The seat was adjusted to a predetermined height to allow for complete knee extension with the ankle flexed at $90^{\circ}$. Toe clips were used and the participants were required to remain seated for the duration of the test. The participants perform a cycling warm up for 5 minutes at a 
Iş1k, Ö., Ersöz, Y., Pazan, M., \& Ocak, Y. (2015). The effect of motivational music on wingate anaerobic test performance. International Journal of Human Sciences, 12(2), 513-520. doi: 10.14687/ijhs.v12i2.3254

pedaling rate of 60-70 $\mathrm{rpm}$. Two unloaded 5-second sprints were performed at the end of the third and fifth minutes of the warm-up period. After a 5-minute rest, participants performed the WAnT. The resistance setting for the test was set at 7.5\% of BW in $\mathrm{kg}$. The participants were instructed to pedal as fast as possible for 30 seconds. The participants were verbally motivated during the test for both conditions. Monark anaerobic test computer software program was used for the records of all the information from the bike during the duration of the test (Inbar et al., 1996).

Absolute power values [Maximum Anaerobic Power $\left(\mathrm{M}_{\mathrm{ax}} \mathrm{AP}\right)$, Maximum Anaerobic Capacity (MAC), Minimum Anaerobic Power $\left.\left(\mathrm{M}_{\mathrm{in}} \mathrm{AP}\right)\right]$ were determined by the software on the computer in WAnT. In addition relative power values [Relative Anaerobic Power (RAP), Relative Anaerobic Capacity (RAC)] and Fatigue Index (FI) values were calculated using the following formulas;

$\operatorname{RAP}\left(\mathrm{W} \times \mathrm{kg}^{-1}\right)=\mathrm{M}_{\mathrm{ax}} \mathrm{AP} \times(\mathrm{BW})^{-1}$

$\mathrm{RAC}\left(\mathrm{W} \times \mathrm{kg}^{-1}\right)=\mathrm{MAC} \times(\mathrm{BW})^{-1}$

FI $(\%)=\left[\left(\mathrm{M}_{a x} \mathrm{AP}-\mathrm{M}_{\mathrm{in}} \mathrm{AP}\right) \times \mathrm{M}_{\mathrm{ax}} \mathrm{AP}^{-1}\right] \times 100$.

\section{Collection of the data}

The heights and body weights of the participants were measured as they were wearing shorts and as barefoot by using the SECA stadiometer having the sensitivity of 0.01 . As a result of these measurements was calculated are their body mass indexes. The WAnT performance measurements of the participants were performed in without music (pre-test) and with motivational music $(>120$ bpm) (last test) condition. The relative humidity, temperature and music sound level in both conditions in which the study measurements were made were measured with the DT8820 digital multi-functional environment meter. In laboratory was determined as the relative humidity \% 50, the temperature $26^{\circ} \mathrm{C}$ and the sound level 75 decibel.

\section{Statistical analysis of the data}

The normality test of Shapiro-Wilk test was used data obtained. For the determination of the differences among the variables not showing normal distribution, the Wilcoxon Rank Test from the non-parametric tests was used. Results were considered significant with a $95 \%$ confidence interval and results below $\mathrm{p}<0.05$ were considered as significant. In addition, the percentage difference between the measurement results made in two different conditions was calculated with the following formula for each variable;

$\% \Delta=[$ (With music - Without Music) $/$ Without Music $] \times 100$. 
Işık, Ö., Ersöz, Y., Pazan, M., \& Ocak, Y. (2015). The effect of motivational music on wingate anaerobic test performance. International Journal of Human Sciences, 12(2), 513-520. doi: 10.14687/ijhs.v12i2.3254

\section{Results}

Table 1. Demographic Characteristics of the Participants

\begin{tabular}{ccc}
\hline Variables & $\mathbf{N}$ & $\bar{X} \pm \sigma$ \\
\hline Age (years) & 16 & $23,19 \pm 3,02$ \\
Height (m.) & 16 & $1,77 \pm 0,53$ \\
BW (kg.) & 16 & $78,25 \pm 9,36$ \\
BMI (m/ $\left.\mathbf{k g}^{2}\right)$ & 16 & $25,10 \pm 2,94$ \\
\hline
\end{tabular}

BW= Body Weight, BMI = Body Mass Index, $\bar{X}=$ Mean, $\sigma=$ Standart Deviation,

The age averages of the participants were shown as $23,19 \pm 3,02$ (years), height averages as $1,77 \pm 0,53$

(m.) BW averages as $78,25 \pm 9,36(\mathrm{~kg})$ and BMI averages as $25,10 \pm 2,94\left(\mathrm{~m} / \mathrm{kg}^{2}\right)$ in the table 1 .

Table 2. WAnT performance measurement results of the participants

\begin{tabular}{|c|c|c|c|c|c|c|}
\hline \multicolumn{2}{|c|}{ Variables } & Condition & $\bar{X} \pm \sigma$ & $\mathrm{Z}$ & $\mathbf{P}$ & $\% \Delta$ \\
\hline \multirow{3}{*}{$\begin{array}{c}\text { Absolute } \\
\text { Power } \\
\text { (W) }\end{array}$} & $\begin{array}{c}\mathbf{M}_{\mathrm{ax}} \mathbf{A P} \\
(\mathrm{W})\end{array}$ & $\begin{array}{c}\text { With Music } \\
\text { Without Music }\end{array}$ & $\begin{array}{l}929,39 \pm 156,19 \\
801,52 \pm 146,56\end{array}$ & 3,413 & $0,001^{* *}$ & 17,17 \\
\hline & $\begin{array}{l}\text { MAC } \\
\text { (W) }\end{array}$ & $\begin{array}{c}\text { With Music } \\
\text { Without Music }\end{array}$ & $\begin{array}{l}573,32 \pm 98,85 \\
520,47 \pm 76,07\end{array}$ & 2,741 & $0,006^{* *}$ & 10,59 \\
\hline & $\begin{array}{c}\mathbf{M}_{\mathrm{in}} \mathrm{AP} \\
(\mathrm{W})\end{array}$ & $\begin{array}{c}\text { With Music } \\
\text { Without Music }\end{array}$ & $\begin{array}{l}293,65 \pm 59,09 \\
292,10 \pm 63,94 \\
\end{array}$ & 0,155 & 0,877 & 3,97 \\
\hline \multirow{2}{*}{$\begin{array}{c}\text { Relative } \\
\text { Power } \\
\left(\mathrm{W} \times \mathrm{kg}^{-1}\right)\end{array}$} & $\begin{array}{c}\text { RAP } \\
\left(\mathbf{W} \times \mathrm{kg}^{-1}\right)\end{array}$ & $\begin{array}{c}\text { With Music } \\
\text { Without Music }\end{array}$ & $\begin{array}{l}11,90 \pm 1,54 \\
10,24 \pm 1,49\end{array}$ & 3,413 & $0,001^{* *}$ & 17,17 \\
\hline & $\begin{array}{c}\text { RAC } \\
\left(\mathrm{W} \times \mathrm{kg}^{-1}\right)\end{array}$ & $\begin{array}{c}\text { With Music } \\
\text { Without Music }\end{array}$ & $\begin{array}{l}7,33 \pm 0,81 \\
6,65 \pm 0,60 \\
\end{array}$ & 2,947 & $0,003^{* *}$ & 10,59 \\
\hline \multicolumn{2}{|c|}{ FI (\%) } & $\begin{array}{c}\text { With Music } \\
\text { Without Music }\end{array}$ & $\begin{array}{l}68,11 \pm 5,51 \\
62,96 \pm 8,10\end{array}$ & 1,965 & $0,049^{*}$ & 9,72 \\
\hline
\end{tabular}

${ }^{*}{ }_{\mathrm{p}}<001,{ }^{*} \mathrm{p}<0,05, \bar{X}=$ Mean, $\sigma=$ Standart Deviation, $\% \Delta=$ Difference of Percentage, W $=\mathrm{Watt}, \mathrm{W} \times \mathrm{kg}^{-1}=$ Watt $/$ Kilogram, $\%=$ Percentage, $\mathrm{M}_{\mathrm{ax}} \mathrm{AP}=$ Maximum Anaerobic Power, MAC $=$ Maximum Anaerobic Capacity, RAP $=$ Relative Anaerobic Power, RAC =Relative Anaerobic Capacity, FI =Fatigue Index, $\mathrm{M}_{\mathrm{in}} \mathrm{AP}=$ Maximum Anaerobic Power

While the statistically significant difference was determined among the participants' $\mathrm{M}_{a x} A P$, MAC, RAP, RAC and FI values $(p<0,05)$, it was seen that there was no statistically significant difference among the $\mathrm{M}_{\mathrm{in}} \mathrm{AP}$ values ( $\mathrm{p}>0,05$; Table 2$)$. When the WAnT performance percentage differences of the participants in with and without music conditions were examined, it was seen that there was increase in favor of the condition with music in the $\mathrm{M}_{\mathrm{ax}} \mathrm{AP}$ and $\mathrm{RAP}(\% 17,17)$, MAC and RAC $(\% 10,59)$ and FI $(\% 9,72)$ and $\mathrm{M}_{\text {in }} \mathrm{AP}(\% 3,97)$ values. $(\mathrm{p}>0,05$; Table 2$)$. 
Ișık, Ö., Ersöz, Y., Pazan, M., \& Ocak, Y. (2015). The effect of motivational music on wingate anaerobic test performance. International Journal of Human Sciences, 12(2), 513-520. doi: 10.14687/ijhs.v12i2.3254

\section{Graph 1. Graph of the Absolute Power Values Comparison of the participants}

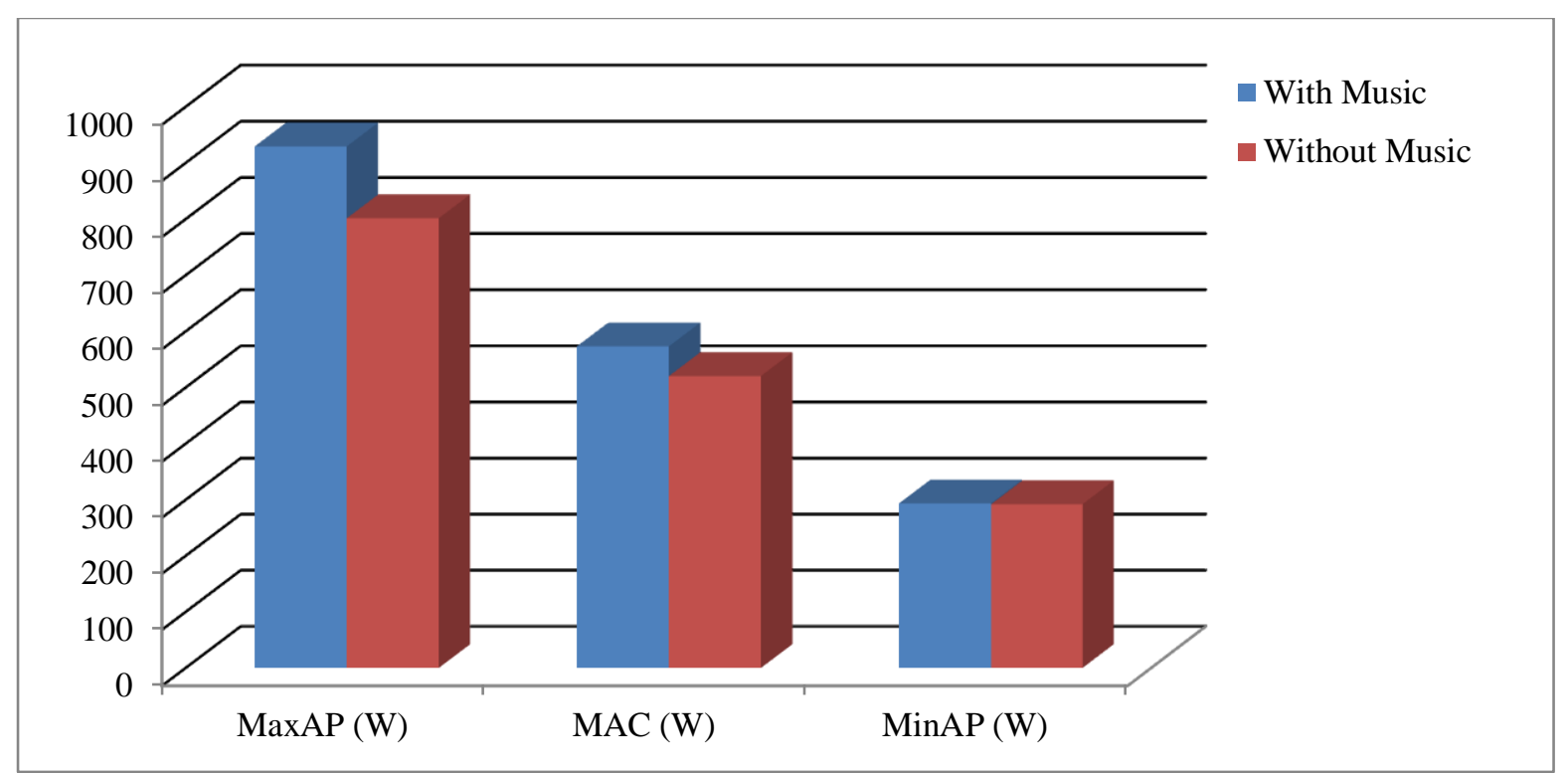

When the participants' absolute power values with and without music conditions were compared; it was determined that there were statistically significant differences among the $M_{a x} A P$ and MAC values $(p<001)$, and it was determined that there was no statistically significant difference among the $\mathrm{M}_{\mathrm{in}} \mathrm{AP}$ values ( $\left.\mathrm{p}>0,05 ; \mathrm{Graph} 1\right)$.

\section{Graph 2. Graph of the Relative Power and FI Values Comparison of the participants}

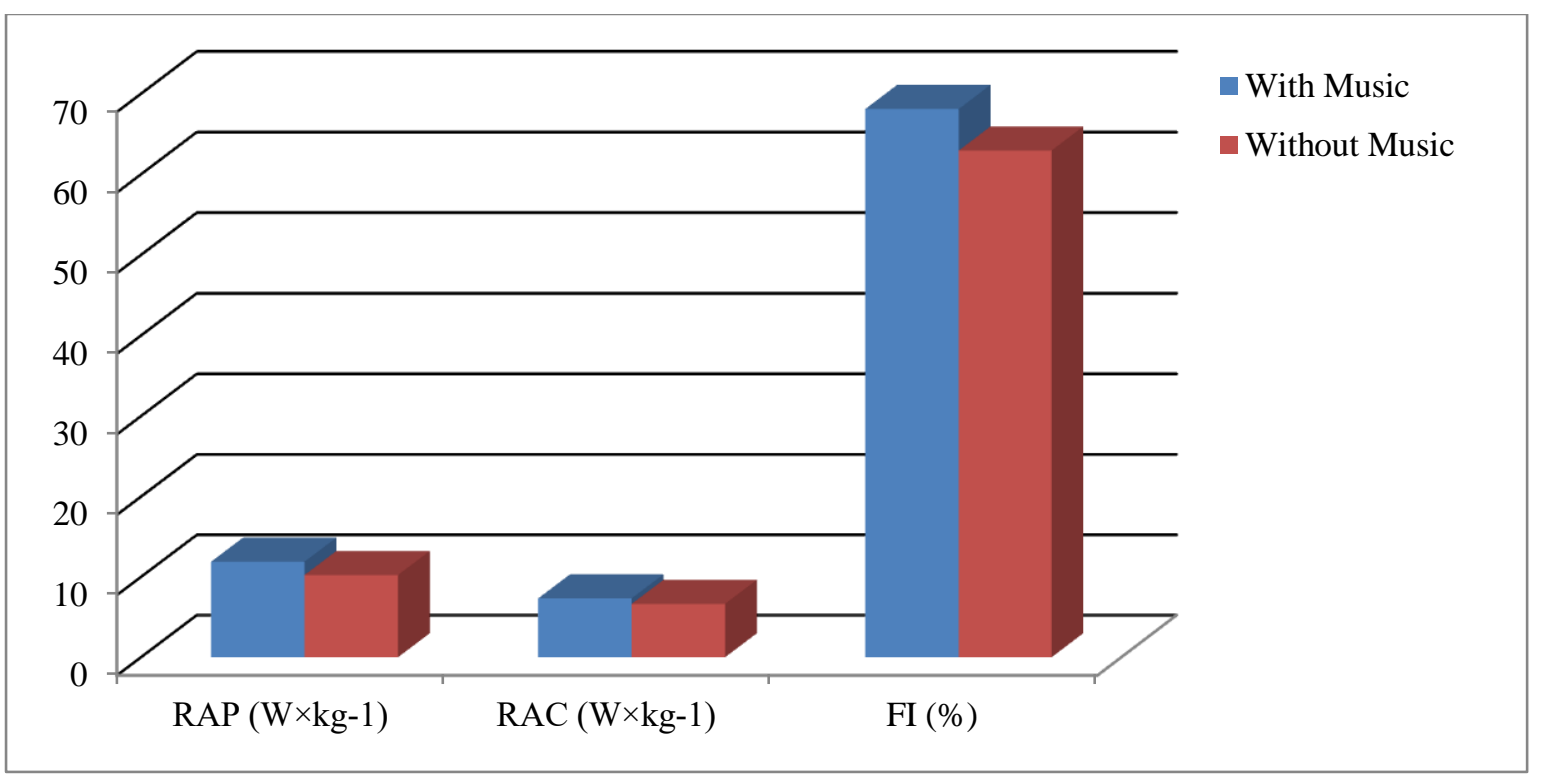

When the participants' relative power values and FI with and without music conditions were compared; it was determined that there were statistically significant differences among the FI, RAP and RAC values ( $p<0,05$; Graph 2). 
Iş1k, Ö., Ersöz, Y., Pazan, M., \& Ocak, Y. (2015). The effect of motivational music on wingate anaerobic test performance. International Journal of Human Sciences, 12(2), 513-520. doi: $10.14687 /$ ijhs.v12i2.3254

\section{Discussion}

The music is commonly used for accompanying to the exercise and sports activities (Koc and Curtseit, 2009). The fast and motivating music should be selected when it is required to motive a sportsman during the power or resistance exercises. The selection of the music type of the individual plays an important role in determining the effect of the music on the exercise capacity. Generally, the music selection aims to optimize the objective of the individual (Eliakim et al., 2012). While in some studies the negative or refreshing effect of the slow tempo music has been determined, it has been also shown that the high tempo music has performance increasing effects (Ferguson et al., 1994; Karageorghis, et al., 1996).

Whether the music has effect or not also differs in the studies examining its effect on the sportive performance (Pujol and Langenfeld, 1999; Atan, 2013). The aim of this study this context is to examine the effect of the motivational music on the WAnT performance. In this study, $\mathrm{M}_{\mathrm{ax}} \mathrm{AP}$, MAC, $\mathrm{M}_{\mathrm{in}} \mathrm{AP}, \mathrm{RAP}, \mathrm{RAC}$ and FI from the anaerobic performance components were examined with the help of the WAnT. While the statistically significant difference was determined among the participants' $\mathrm{M}_{\mathrm{ax}} \mathrm{AP}, \mathrm{MAC}, \mathrm{RAP}, \mathrm{RAC}$ and FI values in with and without music conditions $(\mathrm{p}<0,05)$, it was determined that there was no statistically significant difference among the $\mathrm{M}_{\mathrm{in}} \mathrm{AP}$ values ( $p>0,05$; Table 2). In addition, it was determined that there was increase in favor of the with music condition in the $\mathrm{M}_{\mathrm{ax}} \mathrm{AP}$ and RAP (\%17,17), MAC and RAC $(\% 10,59)$ and FI $(\% 9,72)$ and $\mathrm{M}_{\text {in }} \mathrm{AP}(\% 3,97)$ values. $(\mathrm{p}>0,05$; Table 2$)$.

In the literature, in the studies made with the music and anaerobic performance, generally the $\mathrm{M}_{\mathrm{ax}} \mathrm{AP}$ and MAC values have been evaluated as RAP and RAC and the power and capacity per kilogram have been examined. In the study in which Chtourou et al. (2012) examined the effect of the music during the young sprinters' anaerobic performance warm-up exercises, they determined that there was statistically significant difference among the RAP and RAC values. In the study in which Jarraya et al. (2012) examined the effect of music by making the senior sportsmen realize high density short duration exercise, they determined that there was statistically significant difference among the RAP and RAC values in with and without music conditions. Eliakim et al. (2012) determined that the motivational music has an effect on the repeating sprint ability. It has been determined that the motivational music can be used as a toll for increasing the intensity of the sub-maximal exercises and it has the characteristics of manipulating the effort perception and it has a positive effect to the work to be realized (Elliott, Carr and Orme, 2005). However, in the study in which Atan (2013) examined the effects of the different music protocols (without music, slow music, fast music) on the WAnT performance, he has determined that there was no statistically significant difference among the $\mathrm{M}_{\mathrm{ax}} \mathrm{AP}, \mathrm{MAC}, \mathrm{M}_{\mathrm{in}} \mathrm{AP}$ and $\mathrm{FI}$ values. 
Iş1k, Ö., Ersöz, Y., Pazan, M., \& Ocak, Y. (2015). The effect of motivational music on wingate anaerobic test performance. International Journal of Human Sciences, 12(2), 513-520. doi: 10.14687/ijhs.v12i2.3254

In the study that Chtourou et al. (2012) realized, they have determined that was no statistically significant difference among the FI values. In the study that Jarraya et al. (2012) realized, they have determined that there was no statistically significant difference among the FI values. Our research is different from the study results made in the literature in terms of FI. In our research, the statistically significant difference among the FI values of the participants in with and without music conditions was determined. It is though that this difference arises from the difference among the $\mathrm{M}_{\mathrm{ax}} \mathrm{AP}$ and $\mathrm{M}_{\text {in }} \mathrm{AP}$ values that the participants produced in with and without music conditions.

In the short duration supramaximal exercises, the ergogenic effect of the music can be explained via the psycho-physiological mechanisms (Jarraya et al., 2012). In the high intensity exercises, the supramaximal exercises can be made more entertaining by shifting the music effort perception and also it is thought that it will positively affect the will power. As a result, it has been determined that the motivational music has positive effects on the WAnT performance. However, even though the effect of the motivational music that increases the WAnT performance is observed, it is thought that this effect arises from the psycho-physiological factors (will power, psychological balance, autonomous nervous system, etc.) increasing depending on the motivational music.

\section{Practical Application}

This study shows that the motivational music has positive effects on the sportsmen's performance. Generally the trainings which are boring for the sportsmen and the performance tests can be made entertaining in the accompany of the music and their performances can be increased. The sportsmen and trainers can use the music as the ergogenic aids in the trainings and performance tests.

\section{References}

Ataman, O. G. (2014). The Attitudes of Prospective Music Teachers to School Musical Instrument (Recorder) Courses. International Journal of Academic Research, 6(2), 231-237.

Atan, T. (2013). Effect of music on anaerobic exercise performance. Biology of sport, 30(1), 35-39.

Callaghan, K. T., \& Growney, C. M. (2013). The Impact of Music and Mood on Creative Thinking. Psi Chi Journal of Psychological Research, 18(4), 164-169.

Chang, M. Y., Chen, C. H., \& Huang, K. F. (2008). Effects of music therapy on psychological health of women during pregnancy. Journal of Clinical Nursing, 17(19), 2580-2587.

Chtourou, H., Jarraya, M., Aloui, A., Hammouda, O., \& Souissi, N. (2012). The effects of music during warm-up on anaerobic performances of young sprinters. Science \& Sports, 27(6), 8588. 
Işık, Ö., Ersöz, Y., Pazan, M., \& Ocak, Y. (2015). The effect of motivational music on wingate anaerobic test performance. International Journal of Human Sciences, 12(2), 513-520. doi: 10.14687/ijhs.v12i2.3254

Eliakim, M., Meckel, Y., Gotlieb, R., Nemet, D., \& Eliakim, A. (2012). Motivational music and repeated sprint ability in junior basketball players. Acta Kinesiologiae Universitatis Tartuensis, 18, 29-38.

Elliott, D., Carr, S., \& Orme, D. (2005). The effect of motivational music on sub-maximal exercise. European Journal of Sport Science, 5(2), 97-106.

Ferguson, A. R., Carbonneau, M. R., \& Chambliss, C. (1994). Effects of positive and negative music on performance of a karate drill. Perceptual and motor skills, 78(3c), 1217-1218.

Gacesa, J. Z. P., Barak, O. F., \& Grujic, N. G. (2009). Maximal anaerobic power test in athletes of different sport disciplines. The Journal of Strength \& Conditioning Research, 23(3), 751-755.

Inbar O., Bar-Or O., Skinner J. S. The Wingate Anaerobic Test. Human Kinetics Books, Champaign, IL, 1996.

Jarraya, M., Chtourou, H., Aloui, A., Hammouda, O., Chamari, K., Chaouachi, A., \& Souissi, N. (2012). The effects of music on high-intensity short-term exercise in well trained athletes. Asian journal of sports medicine, 3(4), 233-238.

Karageorghis, C. I., Drew, K. M., \& Terry, P. C. (1996). Effects of pretest stimulative and sedative music on grip strength. Perceptual and motor skills, 83(3f), 1347-1352.

Koc, H., Curtseit, T. (2009). The Effects Of Music On Athletic Performance. Ovidius University Annals, Series Physical Education and Sport/Science, Movement and Health, 9(1), 43-47.

Mohammadzadeh, H., Tartibiyan, B., \& Ahmadi, A. (2008). The effects of music on the perceived exertion rate and performance of trained and untrained individuals during progressive exercise. Facta Universitatis-Series: Physical Education and Sport, 6(1), 67-74.

Perlovsky, L. (2014). The Cognitive Function of Music. Part II. Interdisciplinary Science Reviews, 39(2), 162-186.

Pujol, T. J., \& Langenfeld, M. E. (1999). Influence of music on Wingate Anaerobic Test performance. Perceptual and Motor Skills, 88(1), 292-296.

Schlaug, G., Norton, A., Overy, K., \& Winner, E. (2005). Effects of music training on the child's brain and cognitive development. Annals of the New York Academy of Sciences, 1060(1), 219230.

Terry, P. C., Karageorghis, C. I. (2011). Chariots of Fire: The Role of Music in Sport and Exercise. Sport and exercise psychology: The cutting edge. Morgantown, WV: Fitness Information Technology.

Waterhouse, J., Hudson, P., \& Edwards, B. (2010). Effects of music tempo upon submaximal cycling performance. Scandinavian journal of medicine \& science in sports, 20(4), 662-669.

Yamashita, S., Iwai, K., Akimoto, T., Sugawara, J., \& Kono, I. (2006). Effects of music during exercise on RPE, heart rate and the autonomic nervous system. Journal of Sports Medicine and Physical Fitness, 46(3), 425-430. 